\title{
JUAN B. LAGARDE Y LA POLICÍA SECRETA DE LA CIUDAD DE MÉXICO, 1858-1860*
}

\section{JUAN B. LAGARDE AND THE SECRET POLICE IN MEXICO CITY, 1858-1860}

\author{
Emmanuel RodRíGuez BACA \\ Universidad Nacional Autónoma de México \\ Posgrado en Historia \\ fbberriozabal@hotmail.com
}

\section{Resumen}

El presente artículo analiza el papel de Juan B. Lagarde como jefe de la policía secreta de la ciudad de México durante la guerra civil de Reforma (1858-1860), la importancia de ésta como parte de los cuerpos de control y seguridad que establecieron los gobiernos conservadores de los generales Félix Zuloaga (1858) y Miguel Miramón (1859-1860) para vigilar, perseguir y encarcelar a las personas consideradas como sediciosas y enemigas de sus administraciones. Se destacan los excesos y la eficaz labor de dicho personaje para contrarrestar a los agentes del gobierno constitucional que, durante los tres años del conflicto, conspiraron y trabajaron para promover insurrecciones y la ocupación de la capital por el ejército liberal. Temido, odiado y respetado por la población y por sus adversarios políticos, Juan Lagarde cumplió con la misión que el régimen que emanó del Plan de Tacubaya de 1857 le encomendó.

Palabras clave: guerra de Reforma, ciudad de México, Juan Lagarde, policía secreta, gobierno conservador.

\begin{abstract}
The following article analyzes the role of Juan B. Lagarde as head of the secret police in Mexico City during the civil war of the Reform period (1858-1860), the importance they had in both control and security which were established by the conservative parties of general Félix Zuloaga (1858) and Miguel Miramón (1859-1860) to patrol, persecute and imprison anyone who was seditious or pose a threat your administrations. We see his tireless effort and excessive methods as chief of political police to counter the government agents which during the three years of conflict, conspired and worked against to promote insurgencies. Feared, hated, yet respected by the people and its political adversaries, Juan Lagarde fulfilled the mission that the regime emanated from the Plan of Tacubaya entrusted him.
\end{abstract}

Keywords: Reform Civil War, Mexico City, Juan Lagarde, secret police, Conservative Government.

Información del artículo

Recibido: 3 de diciembre de 2018.

Aceptado: 14 de junio de 2019.

DOI: 10.22201/iih.24485004e.2019.57.67900

* Este trabajo forma parte de mi tesis de doctorado en Historia que actualmente realizó en la Facultad de Filosofía y Letras/Instituto de Investigaciones Históricas de la Universidad Nacional Autónoma de México, de la que son tutores los doctores Silvestre Villegas Revueltas, Ana Rosa Suárez Argüello y María Dolores Lorenzo Río. Para la elaboración de la tesis he contado con el apoyo económico de Consejo Nacional de Ciencia y Tecnología. 


\section{Introducción}

La guerra de Reforma ha sido estudiada desde distintas perspectivas: diplomática, prensa, regional, eclesiástica y militar; siendo esta última a la que la historiografía ha privilegiado. En los últimos años las investigaciones sobre este proceso, y su alcance en los estados de la república, han tenido un despunte considerable; sus resultados son reveladores, ya que han contribuido a explicar las particularidades y las repercusiones de la contienda en las entidades federativas, al tiempo que han permitido a la historiografía ampliar el panorama y la significación de aquélla en el ámbito nacional.

Si bien los estudios sobre la guerra de Tres Años son vastos, es notable la carencia de aquellos que analicen su trascendencia política, social, militar, así como el desasosiego que imperó en la ciudad de México durante los años de 1858-1860. ${ }^{1}$ Así, podemos decir que la historiografía se ha restringido a escribir sobre cuatro hechos en la capital del país en ese periodo: el golpe de Estado de diciembre de 1857, el ataque de Miguel Blanco en octubre de 1858, el sitio de Santos Degollado de los meses de marzo-abril de 1859, y, por último, su ocupación por el ejército liberal en diciembre de 1860.

De lo anterior podemos afirmar que aún faltan investigaciones que permitan dilucidar el impacto que la pugna civil tuvo en la sede del gobierno conservador, los cambios que generó en las prácticas cotidianas de sus habitantes, las relaciones entre los grupos políticos ahí asentados y la actitud que asumieron las autoridades frente a las conspiraciones que en su interior realizaron los agentes y emisarios de la administración constitucional. Así, el estudio de Juan Lagarde y su labor como jefe del cuerpo de policía secreta nos posibilita vislumbrar cómo experimentó la ciudad de México la guerra de Reforma.

El presente artículo se divide en dos partes: en la primera se analiza la formación y los antecedentes políticos y militares del protagonista: Juan

${ }^{1}$ En este rubro Daniel S. Haworth se ha ocupado de analizar cómo afrontó la ciudad de México la conflagración civil y los trastornos que ahí se dieron. Si bien aborda el sistema de reclutamiento forzado, la cuestión fiscal, el papel de la prensa y las relaciones entre el Ayuntamiento y los presidentes Félix Zuloaga y Miguel Miramón, deja de lado aspectos significativos de la guerra interna que vivió la capital, al tiempo que no profundiza en las dimensiones y su impacto en aquélla, por lo que algunos puntos por él tratados son discutibles; en particular, los concernientes a la postura política del cuerpo municipal, su papel como autoridad local y sus relaciones con los encargados del Ejecutivo. Daniel S. Haworth, "Desde los baluartes conservadores: la ciudad de México y la guerra de Reforma (1857-1860)”, Relaciones, v. XXI, n. 84, 2000, p. 95-132. 
Lagarde, elementos indispensables ya que aquéllos nos permiten comprender su actividad como agente de los cuerpos de seguridad en los años siguientes. La segunda estudia su notable labor al frente de la policía política de la ciudad de México en el contexto de la guerra civil de 1858-1860 y la persecución que hizo de los partidarios del gobierno constitucional que en ella permanecieron.

La ciudad de México y el contexto de la guerra civil

La república mexicana inició el año de 1858 en medio de la incertidumbre política como consecuencia del golpe de Estado que se verificó en la capital del país el mes de diciembre anterior. La agitación aumentó el día 11 de enero cuando el general José de la Parra modificó el Plan de Tacubaya del 17 de diciembre, desconoció a Ignacio Comonfort como encargado del Ejecutivo y nombró a Félix Zuloaga general en jefe del Ejército Regenerador. Con esto la ciudad de México se convirtió en un campo de batalla en el que el partido liberal y el conservador intentaron imponer su hegemonía; no obstante, en el alba del 21 de enero el presidente depuesto la abandonó: horas más tarde los pronunciados ocuparon Palacio Nacional, acto con el que, de manera simbólica, consolidaron su triunfo. Este hecho marcó el inicio de la guerra de Reforma, la que habría de alargarse por los próximos tres años.

Asirse de la ciudad de México le permitió a Zuloaga obtener el reconocimiento del cuerpo diplomático extranjero ahí acreditado, que desde la consumación de la independencia aceptaba como legítima a cualquier administración que estuviera en posesión de la capital, no importando si había llegado al poder a través de una asonada militar como ahora ocurría. Mas, la situación en enero de 1858 presentaba una disyuntiva: de manera simultánea al gobierno conservador existió otro itinerante, el liberal representado por Benito Juárez. Con ello, por primera vez desde que México nació a la vida independiente tenía dos gobiernos paralelos que se asumían como legítimos, el primero al amparo del Plan de Tacubaya y el segundo al de la Constitución Política de 1857.

La historiografía de este conflicto ha destacado que, desde su inicio, tanto el ejército liberal como el conservador procuraron, por distintos intereses, alejar las operaciones militares de la ciudad de México, las que se desarrollaron principalmente en los estados del centro-norte y occidente. 
Esta situación ocasionó que aquélla no sufriera los estragos de la contienda con la misma magnitud que otras entidades, lo que no significó que se disociara de ésta; sin embargo, hizo frente a una guerra particular, a la que se vivió en su interior al ser asiento de uno de los gobiernos que se asumían como legítimos, y que se reflejó de distintas maneras, entre otras el temor constante a una incursión del ejército enemigo, levas, intentos de motines, revueltas y conspiraciones, desasosiego que en gran medida se debió al eficaz trabajo que ahí realizaron los agentes constitucionalistas. ${ }^{2}$

Lo anterior obligaría a Zuloaga a tomar las medidas pertinentes para hacerle frente a los emisarios, impedir que sus conjuras se consumaran; de ahí que reflexionó sobre la pertinencia de establecer un cuerpo de policía secreta en la sede de su gobierno. Así, el presente artículo se divide en dos partes: la primera presenta la formación y los antecedentes políticos y militares del protagonista, Juan Lagarde, elementos indispensables para comprender su actividad en el contexto de la guerra de Reforma. En la segunda, se estudia la labor de dicho personaje al frente de la policía secreta de la ciudad de México entre los años de 1858 y 1860.

Una vez que Félix Zuloaga asumió la presidencia, uno de los problemas que enfrentó fue qué hacer con los prisioneros de Estado que se encontraban en las cárceles de la ciudad de México, entre los que descollaban conocidas figuras del ámbito nacional. El problema no era menor, pues el general sonorense era de la idea de que si les otorgaba la libertad serían un riesgo para su administración, al presumir que se incorporarían al ejército de la coalición de estados que, en defensa de la Constitución de 1857, se estaba organizando en el centro del país.

Para resolver lo anterior se recomendó a Zuloaga que otorgara la libertad a todos los presos políticos, medida con la que daría una prueba de "generosidad [y que] dará más lustre a [la] causa". ${ }^{3}$ No obstante, lejos

${ }^{2}$ Marta Eugenia García Ugarte, Poder político y religioso. México siglo XIX, 2 v., México, H. Cámara de Diputados/Universidad Nacional Autónoma de México/Miguel Ángel Porrúa, 2010, v. I, p. 722; Carmen Blázquez, Veracruz liberal, 1858-1860, México, El Colegio de México/Gobierno del Estado de Veracruz, 1986, p. 70-72; Silvestre Villegas Revueltas, El liberalismo moderado en México, 1852-1864, México, Universidad Nacional Autónoma de México, Instituto de Investigaciones Históricas, 2015, p. 202; Miguel Blanco, Rectificaciones históricas. Colección de artículos escritos por el C. Miguel Blanco, México, J. S. Ponce de León, impresor, 1871, p. 63; y William John Ross, The Role of Manuel Doblado in the Mexican Reform Movement 1855-1860, Austin, University of Texas, 1967, p. 265.

${ }^{3}$ José María Guerra, carta a Félix Zuloaga, Querétaro, 2 de febrero de 1858, en Archivo Félix Zuloaga, Universidad Iberoamericana, caja. 3, documento, 1025 (en adelante, AFZ-UIA). 
de liberarlos, el gobierno comenzó una cruzada en contra de los personajes vinculados con su contraparte liberal que permanecieron en la ciudad de México, a quienes se acusó de enviar al puerto de Veracruz, sede de aquél, informes sobre la situación política, y militar que ahí prevalecía, de promover conspiraciones y la agitación entre las guarniciones con la intención de facilitar al ejército federal su ocupación. ${ }^{4}$

La situación que hemos descrito propició que los periódicos alertaran a Zuloaga de las reuniones que con "grande descaro" se realizaban en casas particulares y en espacios públicos, al tiempo que le demandaron procesar a las personas que en ellas participaran. ${ }^{5}$ Es evidente que al gobierno no le eran desconocidas; consciente de ello y de la necesidad de acabar con las conjuras y cualquier intento de sedición, urgió la organización de una policía política o secreta, dirección que ofreció al gobernador del Distrito Federal, Miguel María Azcárate. Éste se excusó de aceptarla argumentando que sólo deseaba atender los aspectos administrativos y la seguridad de la demarcación, esto es las funciones de "policía y buen gobierno", tales como la limpia de calles, el fomento de las escuelas y la urbanidad de sus habitantes. ${ }^{6}$

${ }^{4}$ Carmen Blázquez, Miguel Lerdo de Tejada: un liberal veracruzano en la política nacional, México, El Colegio de México, 1978, p. 125; y de la misma autora Veracruz liberal..., p. 88-89.

5 "Conspiraciones" y "Junta de conspiradores", La Sociedad, 28 de enero y 7 de marzo de 1858, p. 3; Joaquín Castro, carta al ministro de Guerra, México, 22 de marzo de 1858, Archivo Histórico de la Secretaría de la Defensa Nacional, Operaciones Militares, exp. 5648, f. 1-5 (en adelante, AHSDN-OM), y Emilio Arellano, La nueva república. Ignacio Ramírez, el Nigromante, México, Planeta, 2012, p. 53.

${ }^{6}$ Véase Proceso instruido a los ex-ministros de Estado, señores D. Luis G. Cuevas, D. Manuel Díez de Bonilla, D. Manuel Piña y Cuevas y D. Teófilo Marín, y ex-gobernador del Distrito D. Miguel María Azcárate, acusado de usurpación del poder público por las funciones que desempeñaron en la República entre los años de 1858 y 1860, México, Imprenta de José Mariano Lara, 1861, p. 161. En relación con la acepción del concepto de policía en México, Diego Pulido realizó un estudio sobre los cambios semánticos que tuvo esta "voz" entre la segunda mitad del siglo XVIII y la primera del XIX; es decir, desde la concepción tradicional de "buen gobierno", que se encargaba de la limpieza, alumbrado, aseo, belleza, cortesía y urbanidad en la ciudad, hasta el moderno de comienzos del xix, para referirse a la "Policía de seguridad", que se aplicó desde la guerra de Independencia, la que se vinculó a tareas de espionaje y especializó "en descubrir a los conspiradores". En palabras del autor, "para la década de 1830 era un hecho que el término policía estaba estrechamente ligado con los cuerpos de seguridad". De este periodo, Jorge Nacif refiere que había dos secciones de policía: la administrativa, que dependía del ayuntamiento, y la militar que lo hacía del ejército. Para él, la fuerza policiaca se creó con base en las "situaciones conflictivas" del país y debido a que los habitantes de la capital "enfrentaban el peligro latente de perder sus propiedades o sus vidas, ya fuera por levantamientos armados, por inconformes del gobierno, o por las invasiones extranjeras". 
Debido a esta negativa, la responsabilidad recayó en el coronel Juan B. Lagarde, designación que, creemos, Zuloaga no hizo de manera irreflexiva; lejos de esto había considerado varios elementos. Uno de ellos fue su apego al partido conservador; otro, que no era la primera vez que quedaba al frente del cuerpo de policía secreta: de éste se había hecho cargo en el año de 1853, durante la dictadura de Antonio López de Santa Anna; no obstante, si bien Lagarde tenía una larga trayectoria, su reputación no era muy fiable. En este punto es pertinente hacer la siguiente pregunta, ¿quién era este personaje y cuáles eran sus antecedentes políticos?

\section{El "temido barba rubia": inicios y formación del agente de policía}

Juan Bautista Lagarde Gassion era originario del puerto de Veracruz. ${ }^{7}$ Fue en este lugar en donde se inició en la carrera de las armas al ingresar, en el mes de marzo de 1839, como escribiente del cuerpo político de la Armada. A las pocas semanas de haberse dado de alta, solicitó una licencia con sueldo por cuatro meses para trasladarse a la ciudad de México, petición que le fue negada por sus superiores, con el argumento de que Juan Bautista "era desafecto al servicio y al trabajo"; fue gracias a la mediación de su madre que obtuvo dicho permiso. Mas antes de que esto se verificara, fue detenido en Veracruz: abandonar el arresto que en dos ocasiones le habían impuesto las autoridades fue el delito que se le imputó. Esta conducta, es

Diego Pulido Esteva, "Policía: del buen gobierno a la seguridad, 1750-1850”, Historia Mexicana, n. 239, 2011, p. 1595-1642, y Jorge Nacif Mina, La policía en la historia de la ciudad de México (1524-1928), México, Departamento del Distrito Federal, Secretaría General de Desarrollo Social, 1986, p. 20-22.

${ }^{7}$ Juan Bautista nació en el año de 1822. Fue hijo de José Lagarde y Jaenne - Juana en otros documentos- Gassion. En las actas de bautismo y matrimonios de los hermanos Lagarde, se registra indistintamente Gaspin, Gassin o Gassion para referirse a su segundo apellido. Para el caso del padre, José Lagarde, se asienta que era español, hijo de Francisco Lagarde y María Leante ambos de nacionalidad francesa, mas otras actas mencionan que era natural del reino de Francia. De la madre se apuntó que era originaria de Veracruz, hija de españoles. Del matrimonio Lagarde Gassion nacieron Francisco, José, Javier y Luis; los tres últimos, al igual que Juan, tomarían parte activa en la política mexicana entre los años de 1848-1860. Archivo General de la Nación, Pasaportes y Cartas de Seguridad, v. 52, exp. 178, f. 273, y v. 44, exp. 31, f. 331; y Hoja de servicios del general brigadier Juan B. Lagarde, AHSDN, Cancelados, exp. III/3-916, t. 1, f. 2 y 11. 
decir su aversión a las órdenes superiores y las faltas al servicio, sería una constante en su trayectoria militar. ${ }^{8}$

Fue hasta finales de 1839, una vez que cumplió su condena, que Lagarde partió a la ciudad de México, en donde se incorporó al Sexto Regimiento de Caballería. En poco tiempo ascendió rápidamente en el ejército; para el año de 1843 había obtenido el grado de capitán. Lo anterior nos lleva a presumir que estas promociones las obtuvo no por los servicios militares prestados, exiguos en realidad, sino debido a los vínculos con destacados personajes de la política, uno de ellos su coterráneo Antonio López de Santa Anna. No conocemos en qué momento o circunstancias comenzó la relación entre los jarochos, lo cierto es que para 1844, el segundo, en su carácter de presidente de la República, ordenó que Juan Lagarde se incorporara a su Estado Mayor como ayudante personal. ${ }^{9}$ Es viable creer que esta designación se debió, además del origen porteño de ambos, a posibles lazos comerciales o de parentesco entre la familia de Lagarde y la de Santa Anna en Veracruz. A partir de entonces, la relación entre estos personajes se hizo más fuerte, situación que, por otro lado, también los llevó a compartir adversidades, sobre todo las de don Antonio.

Las fuentes consultadas aportan escasa información sobre las actividades de Lagarde durante los años de 1845 a 1847; lo que sí sabemos es que una vez que se declaró la guerra entre México y los Estados Unidos, acompañó a López de Santa Anna en la campaña del norte, en la que su conducta militar fue censurada. El coronel Francisco Ávalos, lo acusó de deserción por lo que solicitó que se le abriera una causa militar, de lo que resultó que un consejo de guerra lo degradara y diera de baja, mas esta sentencia no se cumplió debido a la intercesión que hizo en su favor el general José Joaquín de Herrera. ${ }^{10}$

${ }^{8}$ AHSDN, Cancelados, exp. III/3-916, t. 1, f. 52, 55, 57, 59, 65 y 67.

9 Antonio López de Santa Anna, carta al ministro de Guerra, México, 14 de junio de 1844, AHSDn, Cancelados, exp. III/3-916, t. 1, f. 87. Un mes y medio después de esta designación, el 27 de julio de 1844, Lagarde contrajo matrimonio con María de la Luz Sánchez Vallejo en la parroquia de la Santa Veracruz de la ciudad de México. Tuvieron cinco hijos: María Antonia Dolores Rafaela, María del Rosario Eufrosina, Juan Bautista, Carlos Alberto Regino y Lorenzo José Francisco de Paula. Véase: familysearch.org/ark:/61903/3:1:S 3HY-XKRC-2Y? $i=570 \& w c=3$ PXX $-\quad$ PTL\%3A $122652201 \% 2 \mathrm{C} 132411001 \% 3 \mathrm{Fcc} \%$ 3D1615259\&cc $=1615259$

${ }^{10}$ En la causa que las autoridades militares le hicieron por este delito, se apuntó que en la ciudad de San Luis Potosí, Juan Bautista recibió la orden de ir a Matehuala; no obstante, este precepto se dirigió a Querétaro, ciudad a la que llegó en el mes de octubre de 1847, 
Lejos de aplicársele la pena referida, en Querétaro Juan Bautista recibió de Manuel de la Peña y Peña, entonces presidente de México, la orden de trasladarse a la capital del país e incorporarse al Cuerpo de Policía, en el que fue dado de alta el día 1 de febrero de 1848. Este hecho es significativo ya que, a partir de entonces, su injerencia e influencia en asuntos tocantes a la seguridad y vigilancia de la ciudad de México crecieron de manera considerable, convirtiéndose en un eficaz agente al espiar y perseguir a todas aquellas personas consideradas disidentes por los gobiernos nacionales en turno. No dudamos de que el ejercicio de estas faenas le permitiera tratar con los grupos políticos y las autoridades locales, así como estar en constante contacto con los sectores populares y conocer sus barrios, experiencias que le serían de utilidad en el transcurso de la guerra de Reforma. ${ }^{11}$ El desempeño de este cargo le ganó a Lagarde Gassion amistades, pero también un sinfín de aversiones políticas y enemigos personales.

Una de sus actuaciones más conocidas de este periodo ocurrió en el mes de enero del año 1853, cuando el entonces encargado del Ejecutivo Juan Bautista Ceballos disolvió las cámaras, lo que había originado la inconformidad de diputados y senadores. Los primeros, reunidos en casa del licenciado Francisco M. de Olaguíbel, no sólo protestaron, sino que promovieron una causa contra el presidente, quien de inmediato mandó a la policía política para aprehenderlos. El encargado de cumplir esta orden fue Lagarde, quien se presentó en dicho domicilio a "intimidarles de parte del señor presidente" para pasar arrestados a la cárcel de la Diputación. A pesar de la resistencia que opusieron, al final los personajes ahí presentes, entre ellos José María Lacunza y José María Lafragua, fueron conducidos a la prisión. ${ }^{12}$

En este punto es pertinente mencionar que los excesos de Lagarde como policía no se circunscribieron a la capital ya que éstos se extendieron a otras entidades, una de ellas el vecino Estado de México, en donde cometió toda clase de tropelías, lo que había originado la inconformidad del gobernador, subprefectos y hacendados. La desazón fue tal, que el subprefecto de Yautepec se quejó de que el jefe de policía había llegado a esta villa al frente de un piquete de policía del Distrito sin que le indicara el objeto de su visita cometiendo algunos abusos; por su parte, los hermanos Mosso, acaudalados

probablemente para incorporarse a las fuerzas de López de Santa Anna. AHSDN, Cancelados, exp. III/3-916, t. 1, f. 103-119.

${ }^{11}$ AHSDn, Cancelados, exp. III/3-916, t. 1, f. 19.

12 "Senadores y Diputados", El Universal, 22 de enero de 1860, p. 3. 
comerciantes de la tierra caliente, manifestaron su molestia por el cateo que aquél había hecho en su casa en la hacienda de Atlihuayan con el pretexto de buscar a "una persona determinada", que según él se refugiaba en esa propiedad. ${ }^{13}$

Como ya se mencionó, durante los distintos periodos en que Antonio López de Santa Anna ocupó la presidencia, Juan Lagarde fue uno de sus incondicionales, por lo que recibió más de una deferencia. En 1853, como apunta Will Fowler, el primero formó su gabinete con conservadores y santannistas, tendencia que también se reflejó en los nombramientos que hizo de las autoridades de la ciudad de México, tanto con el gobernador del Distrito Federal como con las personas que integraron el Ayuntamiento y otros funcionarios, siendo uno de ellos el propio Juan Bautista, a quien designó comandante de escuadrón del Cuerpo de Policía. ${ }^{14}$

Ahora bien, Anselmo de la Portilla señala que una de las prioridades de López de Santa Anna durante su última administración fue la de organizar en la capital un cuerpo de policía secreta para vigilar a las personas que le inspiraban desconfianza. Así, a Lagarde se le encomendó entonces espiar a "los sospechosos" de conspirar contra el régimen, convirtiéndose, con base en la acusación del general Francisco Ávalos, "en un infame esbirro y uno de los hombres más serviles del tirano". ${ }^{15}$ En efecto, la historiografía ha mencionado que la policía política durante la dictadura santannista se caracterizó por cometer abusos desmedidos pues, sin más averiguación que “delaciones y venganzas privadas”, aprehendió, envió a prisión o desterró a un número considerable de enemigos políticos. ${ }^{16}$

Fue en este periodo (1853-1855) cuando comenzó a generarse la animadversión entre Lagarde y el periodista Francisco Zarco. En sus informes,

13 “Los Sres. Mossos”, y “Comandancia general de México”, El Monitor Republicano, 10 y 16 de marzo de 1851, p. 4 y 3.

${ }^{14}$ Will Fowler, Santa Anna, Xalapa, Universidad Veracruzana, 2010, p. 373, y Santiago Blanco, carta a Juan Lagarde, México, 13 de junio de 1854, AHSDn, Cancelados, exp. III/3-916, t. 1, f. 25.

${ }^{15}$ Anselmo de la Portilla, Historia de la revolución de México contra la dictadura del general Santa Anna, 1853-1855, México, Imprenta de Vicente García Torres, 1856, p. 9 y 189; María del Carmen Vázquez Mantecón, Santa Anna y la encrucijada del Estado. La dictadura: 1853-1855, México, Fondo de Cultura Económica, 1986, p. 99, y Francisco Ávalos, carta al gobernador de Veracruz, Acayucan, 1 de octubre de 1855, AHSDn, Cancelados, exp. III/3-916, t. II, f. 4.

${ }^{16}$ De la Portilla, Historia de la revolución de México..., p. 11, y Conrado Hernández López, Militares y conservadores en la Reforma y el Segundo Imperio (1857-1867), México, El Colegio de México, 2001, p. 124. 
el primero había acusado al segundo de "sedicioso" por las críticas que desde El Siglo Diez y Nueve, diario del que era editor, hacía al gobierno, motivo por el que en más de una ocasión lo persiguió e impuso multas económicas. Esta enemistad aumentaría con los años y sería durante la guerra de Reforma cuando alcanzaría su punto más álgido. Como reconocimiento a sus eficientes servicios al frente de la policía, Antonio López le concedió a Juan Bautista el grado de teniente coronel.

La participación de Lagarde en este periodo persiguiendo a los disidentes políticos del régimen fue significativa; esto, creemos, fue el motivo por el que en septiembre de 1854 López de Santa Anna lo nombró su "Ayudante personal Honorario". Sin embargo, los días del segundo al frente de la nación estaban por llegar a su fin debido al movimiento que había estallado en el pueblo de Ayutla en el mes de marzo que lo desconoció como presidente; cuando éste se extendió por gran parte del país su Alteza Serenísima abandonó la ciudad de México en agosto de 1855. Muchos de sus principales colaboradores lo acompañaron a Veracruz, siendo uno de ellos Lagarde, cuya casa, al igual que la de otros funcionarios, fue apedreada por la población como una muestra de indignación contra aquellos que habían "abusado de la tiranía". ${ }^{17}$

A diferencia de su protector, Lagarde Gassion no pudo salir de la república ya que fue hecho prisionero en las inmediaciones de Orizaba cuando a bordo de una diligencia, "disfrazado de clérigo y sin la tupida barba rubia tan conocida en México", pretendía llegar al puerto de Veracruz. ${ }^{18} \mathrm{Al}$ enterarse de su captura, los liberales de la capital solicitaron al gobierno que a la brevedad se le juzgara, y en caso de merecerlo, se le ahorcara, castigo que consideraban necesario por la crueldad y los excesos que éste cometió como comandante de la policía. Su demanda no fue atendida; no obstante, se le envió a la fortaleza de San Juan de Ulúa, donde debía permanecer hasta que la administración triunfante determinara su destino; días después se ordenó su trasladado a la ciudad de México para ponerlo a disposición del juez del ramo Criminal, quien tendría que juzgarlo. ${ }^{19}$

${ }^{17}$ AhsDn, Cancelados, exp. III/3-916, t. 1, f. 142, y Regina Tapia Chávez, Las “jornadas” de agosto de 1855 en la ciudad de México. Un estudio de caso de los mecanismos de lo político, y del discurso político de lo social, México, Universidad Nacional Autónoma de México, Facultad de Filosofía y Letras, 2010, p. 135.

${ }^{18}$ Juan B. Lagarde, carta al ministro de Guerra, San Juan de Ulúa, Veracruz, 12 de octubre de 1855, AHSDN, Cancelados, exp. III/3-916, t. II, f. 2, 16 y 19; "El hábito no hace al monje”, y "Prisión”, El Republicano, 25 y 27 de septiembre de 1855, p. 3.

${ }^{19}$ Ezequiel Montes, carta al ministro de Guerra, México, 10 de enero de 1856, AGN, Justicia, v. 548, exp. 46, f. 146-147, 294 y 296. 
Antes de que la orden mencionada pudiera efectuarse, el día 12 de febrero de 1856 aprovechando un pronunciamiento de la guarnición del puerto de Veracruz en favor del Plan de Zacapoaxtla, ${ }^{20}$ Lagarde se escapó y refugió en la fragata de bandera francesa Penélope, en la que se hizo a la mar con destino a La Habana el 27 de abril. ${ }^{21}$ El viaje lo realizó en compañía de Antonio Haro y Tamariz, Leonardo Márquez y Luis G. Osollo, todos ellos perseguidos por el gobierno de Ignacio Comonfort, personajes con los que años más tarde, una vez iniciada la guerra civil, habría de converger en defensa de la administración conservadora. Con base en el periódico El Ómnibus, se sabe que la embarcación atracó en la isla caribeña a finales del mes de mayo. ${ }^{22}$

No conocemos las actividades que Lagarde realizó en Cuba; sin embargo, es un hecho que se mantuvo informado del devenir de los acontecimientos políticos de la República y en espera de la oportunidad para regresar a ella, la que se presentó a mediados de 1857, antes del golpe de Estado del mes de diciembre. De lo que sí tenemos evidencia es que reapareció en escena en la ciudad de México en enero de 1858, cuando formó parte de las tropas que desconocieron a Comonfort y de las que, inclusive, comandó una sección de infantería en las inmediaciones del convento de San Lorenzo. ${ }^{23}$

Juan B. Lagarde y la policía secreta de los gobiernos tacubayistas

Después de describir la trayectoria de Juan B. Lagarde entendemos por qué Félix Zuloaga lo consideró la persona apropiada para desempeñarse como jefe de policía, todo ello a pesar de que era un hombre de no grato recuerdo en algunos sectores de la capital, pues lo acompañaba "el odio popular". Su designación, entonces, respondió a la necesidad del gobierno de facto de

${ }^{20}$ El Plan Zacapoaxtla se proclamó el 12 de diciembre de 1855 en la población del mismo nombre en el estado de Puebla. Dentro de sus postulados desconoció al gobierno suriano que había emanado de la revolución de Ayutla, al tiempo que proclamó las Bases Orgánicas de 1843.

${ }^{21}$ Sublevación del presidio de S. Juan de Ulúa, El Siglo Diez y Nueve, 19 de febrero de 1856, p. 4; "Hechos diversos" y "Veracruz", El Republicano, 21 y 25 de febrero de 1856, p. 2 y 4.

${ }^{22}$ Jan Bazant, Antonio Haro y Tamariz y sus aventuras políticas 1811-1869, México, El Colegio de México, 1985, p. 134-137; "La fragata Penélope” y "Mexicanos llegados a La Habana”, El Ómnibus, 3 de mayo y 5 de junio de 1856, p. 3 y 2, y "Celebridades llegadas a La Habana", El Republicano, 4 de junio de 1856, p. 4.

23 "De última hora", El Siglo Diez y Nueve, 13 de enero de 1858, p. 3. 
un hombre con su experiencia y conocimientos de la ciudad, tanto de sus habitantes como de los barrios, sin olvidar que había sido el encargado de la policía secreta de la dictadura de López de Santa Anna, en la que dio muestras de efectividad. Por otra parte, no descartamos que entre Zuloaga y el veracruzano existiera un vínculo de camaradería, el que se habría iniciado en 1852, cuando el primero era regidor del Ayuntamiento de la ciudad de México y el segundo, miembro del cuerpo de seguridad, relación que bien pudo estrecharse durante el régimen santannista, en el que ambos figuraron como allegados a don Antonio.

Es importante destacar en este punto que a pesar de los vaivenes políticos sucedidos en el trienio conservador de 1858 a 1860, que implicaron cambios de presidentes, ministros y otros empleados del gobierno, Lagarde habría de mantenerse como encargado de la policía secreta e incluso - como señalaron los vecinos de la capital - tuvo por momentos una voluntad caprichosa que se sobrepuso a la de Félix Zuloaga, Miguel Miramón y sus respectivos gabinetes. ${ }^{24}$ Se convirtió, pues, en un personaje inamovible e indispensable para los referidos presidentes.

Juan Lagarde tomó posesión de su puesto como jefe de la policía política el 31 de enero de 1858, suceso que el Ministerio de Gobernación participó al cuerpo municipal para que a partir de ese momento le abonara la paga por su empleo. ${ }^{25}$ Tan pronto como lo hizo, y con el apoyo de sus hermanos José Miguel y Luis Lagarde —este último coronel-, de los capitanes Sebastián Rubio y Juan Valdés, así como de los alféreces Agustín Miranda, Sabás Pérez, Antonio Arroyo, José María Peña y José María Perdomo, mantuvo una vigilancia "suspicaz e incesante", ya destruyendo imprentas clandestinas, persiguiendo y reduciendo a prisión a los individuos de quienes se sospechara - o se señalase-, a contrarios a la administración y a los "que tenían el delito de pensar", los que no recibieron garantías, como acusó Francisco Zarco, y muchos de los cuales fueron a parar a las celdas de las cárceles de la Acordada o de la militar de Tlatelolco. ${ }^{26}$

24 “Destitución de empleados", La Reforma, 18 de enero de 1861, p. 2.

${ }^{25}$ Archivo Histórico del Distrito Federal, Ayuntamiento y Gobierno del Distrito, Serie Actas de Cabildo, v. 180A, f. 44 (en adelante, AHDF); y "El coronel D. Juan B. Lagarde”, La Sociedad, 6 de febrero de 1858, p. 3.

26 "Editorial", Boletín de Noticias, 25 de diciembre de 1860, p. 1-2. Durante la guerra de Reforma la cárcel de Tlatelolco se convirtió en la más vigilada, ya que ahí se recluyó a connotados prisioneros políticos. Sobre esta cárcel el general Miguel María de Echeagaray, prisionero político, expresó: "La mayor parte de los liberales conocen bien la prisión de Estado o mejor dicho el presidio de Santiago Tlatelolco, por lo que me excuso decir lo que en ella se 
Al hostigamiento de la policía no permanecieron ajenas "las personas más insignificantes”, en otras palabras: a todo el vecindario, tanto el que habitaba el centro de la capital como el que vivía en los barrios periféricos, a quienes se les "expió hasta su fisonomía", es decir, sus expresiones y apariencia para ver si éstas revelaban o delataban algún vínculo con los liberales. ${ }^{27}$ Es evidente que la vigilancia del gobierno en las calles tendría que intensificarse a consecuencia de la guerra civil, más porque la ciudad de México se convirtió en un centro de operaciones en el que los agentes constitucionalistas, durante los tres años del conflicto, conspiraron y patrocinaron levantamientos en contra de la administración que emanó del Plan de Tacubaya.

Si bien los periódicos que circulaban en la sede del gobierno de Zuloaga enaltecían las victorias del ejército conservador en el interior del país, en contraparte los diarios liberales que se publicaban en el puerto de Veracruz propagaban informes sobre el estado de alarma que prevalecía en la capital, así como del constante rumor de que ahí, de un momento a otro, se alzaría algún cuerpo de su guarnición al grito de "Viva la Constitución" y entonces "ardería Troya". ${ }^{28}$ Algo había de cierto en las palabras impresas por El Progreso; de alguna manera en sus páginas se patentizaba que los emisarios liberales, liderados entonces por Miguel Lerdo de Tejada, promovían revueltas en el interior de aquélla.

La historiografía de este periodo registra que para junio de 1858 las relaciones entre el ministro estadounidense John Forsyth y Zuloaga se vol-

sufre”. Una de las carencias más grandes en ésta fue el alimento; por Ignacio Ramírez, preso en esa cárcel, se sabe que algunos reos de Estado se alimentaban sólo de "cáscaras de papa y arroz hervido". Miguel María Echeagaray, Apuntaciones para la defensa del general Echeagaray escritas por el mismo, Guanajuato, Impr. Albino Chagoyán, 1861, p. 88-89, y Emilio Arellano, Ignacio Ramírez, el Nigromante. Memorias prohibidas, México, Planeta, 2009, p. 86.

27 "La clase pobre de la sociedad" y "La prensa y sus temores", El Constitucional, 21 de febrero y 7 de marzo de 1861, p. 1; y "Editorial”, Boletín de Noticias, 25 de diciembre de 1860, p. 1. Luis Fernando Granados y Torcuato S. Di Tella explican que el sureño barrio de San Pablo era uno de los que formaban el menu peuple, que aglutinaba a los estratos más pobres, junto con el de San Juan, San Lázaro, Necatitlán, La Palma, San Antonio Abad, Salto del Agua y Santa Cruz Acatlán, todos ellos alejados de la "vieja ciudad española”. Luis Fernando Granados, Sueñan las piedras. Alzamiento ocurrido en la ciudad de México, 14, 15 y 16 de septiembre de 1847, México, Era/Consejo Nacional para la Cultura y las Artes/Instituto Nacional de Antropología e Historia, 2003, p. 111, y Torcuato S. Di Tella, Política nacional y popular en México, 1820-1847, trad. María Antonia Neira Bigorra, México, Fondo de Cultura Económica, 1994, p. 89.

28 “México", Diario de Avisos (tomado de El Progreso), 5 de julio de 1858, p. 3. 
vieron ríspidas porque el primero confirió asilo a Lerdo de Tejada, ${ }^{29}$ personaje que, según el partido conservador, preparaba un pronunciamiento. Las sospechas no eran infundadas, ya el ministro francés Alexis de Gabriac había anunciado que el liberal veracruzano "se había colocado a la cabeza de un movimiento"; además, aquél contaba con la ayuda de contactos con connotados políticos de la capital, entre ellos Manuel Romero Rubio, Ramón Guzmán Ortiz de Zárate, Felipe Sánchez Solís, Ángel Lerdo de Tejada y Francisco Zarco, para recaudar los recursos económicos necesarios con la intención de fomentar una revuelta. ${ }^{30}$

Si bien durante el primer año de la guerra y, desde la clandestinidad, los agentes constitucionalistas trabajaron con tesón para provocar una insurrección, sus faenas no pasaron desapercibidas. En el mes de junio, a través de un anónimo, Unos amigos verdaderos del gobierno demandaron de Zuloaga acabar a la brevedad con los conspiradores y las conjuras de la ciudad de México, y así se lo expresaron: "Los puros se reúnen en diferentes puntos de la Capital y con el oro extranjero procuran la seducción de la guarnición [...] entre ellos hay empleados del Gobierno que les ayudan, de los que se han dejado en los puestos, no obstante su procedencia, el juramento de la Constitución y su marcada adhesión a los de Ayutla". ${ }^{31}$

En respuesta, y para asegurar la tranquilidad pública, el gobierno incrementó el número de policías secretos, mismos que por sus excentricidades y su poca prudencia no pasaron inadvertidos para la población de la ciudad, que los identificó como hombres de Juan B. Lagarde. De ellos se mencionó:

A todas horas del día y de la noche, recorren las calles unos hombres vestidos, por todo ropaje, con calzón, camisa y sábana o frazada, debajo de la cual llevan armas de fuego y blancas, siendo muchas veces de las prohibidas, como pistolas de calibre de 8 adarmes, vulgarmente llamadas cachorros, estiletes, dagas, tranchetes, puntas de espada y otras cuya portación prohíbe la ley. [Su] aspecto de andar obsceno y mirada torva [que] esconden los rostros en las alas de los sombreros de petates o poblanos, no es para tranquilizar a nadie; y si a ese aspecto repugnante y siniestro, se

${ }^{29}$ Manuel Balbontín, Memorias del coronel Manuel Balbontín, San Luis Potosí, Tip. de la Escuela I. Militar dirigida por Aurelio B. Cortés, 1896, p. 93, y Gerardo Gurza Lavalle, La gestión diplomática de John Forsyth, 1856-1858. Las repercusiones de la crisis regional estadounidense en la política exterior hacia México, México, Secretaría de Relaciones Exteriores, 1997, p. 94-95.

${ }^{30}$ Blázquez, Miguel Lerdo de Tejada: un liberal veracruzano..., p. 127.

${ }^{31}$ Unos amigos del verdadero gobierno, carta a Félix Zuloaga, México, 10 de junio de 1858, AFZ-UIA, caja 2, doc. 28. 
agrega la circunstancia de que van armados como dijimos, nadie que los vea puede juzgarlos otra cosa que facinerosos; $y$ sin embargo, esos hombres son agentes de la autoridad a la que sirven en clase de comisiones secretas. ${ }^{32}$

Para evitar confusiones, Vicente Segura Argüelles, editor del Diario de Avisos, apuntó lo conveniente que sería que los agentes de la policía usaran un uniforme o algún distintivo oculto debajo de una capa, el que únicamente mostrarían para identificarse al momento de registrar una casa o edificio público, o bien al detener a un sospechoso. A pesar de su desfachatez, los hombres comandados por Lagarde fueron eficaces en las comisiones que se les dieron, evidencia de ello es que entre los meses de junio a agosto de 1858 aprehendieron a Juan José Baz, Felipe Buenrostro, José María Picazo, Vicente Rosas Landa, Florencio M. del Castillo, Cosme Varela, Benito Quijano, Manuel Romero Rubio, Ignacio Cumplido, Vicente García Torres, Agustín del Río, José María del Río, Felipe Berriozábal, Vicente Riva Palacio y Manuel Doblado, por mencionar sólo algunos, todos ellos connotados políticos y militares liberales a quienes se acusó de conspirar y por lo mismo fueron enviados a distintas cárceles con la nota de "reos de Estado". ${ }^{33}$

De las anteriores, destacamos las aprehensiones del teniente coronel de la Guardia Nacional Felipe Berriozábal y de Benito Quijano. Del primero, los periódicos de la ciudad de México informaron que había sido apresado la tarde del 26 de julio de 1858 cuando se disponía a montar en un coche. Días más tarde se detalló que en el momento de su detención se le encontraron documentos que acreditaban que "distribuía dinero para la revolución" que proyectaban los círculos liberales de la capital. ${ }^{34}$ En situación semejante se halló el general Quijano, quien el 30 de julio, a escasos días de Berriozábal, fue detenido en su casa de la calle de las Ratas en compañía de otras personas. La policía informó que en el instante de su arresto puso resistencia y que incluso intentó romper unos papeles "comprometedores” que tenía sobre la mesa, de lo que desistió cuando Juan Lagarde lo

32 "Comisiones secretas", Diario de Avisos, 8 de julio de 1858, p. 1.

${ }^{33}$ De éstos, Zarco logró escapar y obtuvo refugió en la casa del ministro de Estados Unidos. Varela y Del Castillo fueron desterrados a Chalco.

${ }^{34}$ Pedro Escudero, carta a Mariano Riva Palacio, México, 30 de julio de 1858, Colección Nettie Lee Benson, Archivo Mariano Riva Palacio, rollo 88, doc. 7223 (en adelante, CNLB-AMRP). Berriozábal, compadre de don Mariano, se fugó de la Diputación a finales del mes de agosto de 1858 con aparente complicidad de sus carceleros. 
amenazó con "saltarle la tapa de los sesos" si no entregaba intactos los documentos, de los que no se dio a conocer el contenido. ${ }^{35}$

La violencia física, a través de la tortura, sería una práctica a la que Lagarde recurriría con frecuencia para intimidar a los conspiradores - ya santannistas, liberales y aun a los miembros del partido conservador-, la que, sin duda, produjo los efectos deseados. Sus exabruptos fueron denunciados por la población y los círculos políticos, así lo hicieron los constitucionalistas quienes, al participar al presidente Juárez la aprehensión y el traslado de Ramón Guzmán, su agente en la capital, a la cárcel de la Acordada, apuntaron: "hemos recibido la ropa de Guzmán y no se puede dudar de que estos hombres, Lagarde más bien dicho ha llegado al extremo de estropearlo. La ropa tiene manchas de sangre". ${ }^{36}$

La celebridad de Lagarde, como jefe de la policía secreta, y como "torturador", rebasó los confines de la capital y todo indica que la forma de conducirse con los enemigos de la administración se convirtió en un referente. Así quedó de manifiesto en una carta que, desde San Luis Potosí, Miramón envío a Zuloaga para hacerle saber que estaban por llegar a la ciudad de México unos comisionados liberales procedentes de Monterrey, por lo que le pidió que al llegar los "recomendara a Lagarde" para que los castigara ejemplarmente. ${ }^{37}$

35 “El Sr. Benito Quijano", La Sociedad, 2 de agosto de 1858, p. 4, y Alexis de Gabriac, informe al gobierno francés, México, 6 de agosto de 1858, en Lilia Díaz, Versión francesa de México: informes económicos 1851-1867, México, Secretaría de Relaciones Exteriores, 1974, v. II, p. 36-37. En palabras del ministro, Quijano pertenecía a "la clase decente de la sociedad [...] [era] muy mal militar y [fiel] a un partido al que toda su familia había siempre repudiado". A la par de esta aprehensión, se informó la de Agustín Alcérreca, de quien se dijo que era agente de los constitucionalistas de Perote; sin embargo, Lagarde dijo que en el momento de su detención no llevaba documentos “comprometedores”, razón por la que preguntó si debía mandarlo a prisión o dejarlo en libertad. Es importante señalar que un hijo suyo, del mismo nombre, se encontraba recluido en la cárcel de Santiago con la nota de reo político. Miguel Piña, carta al ministro de Guerra, México, 12 de agosto de 1858, AHSDN, exp. 5670, f. 1-2, y Agustín Alcérreca (hijo), carta a Félix Zuloaga. Prisión de Santiago, 28 de enero de 1858, AFZ-UIA, caja, 2, doc. 551.

36 “Ángel Cabrera, carta a Benito Juárez, México, 23 de agosto de 1860, p. 736-738", en Benito Juárez, Benito Juárez. Documentos, discursos y correspondencia, 12 v., edición, selección y notas de Jorge L. Tamayo, México, Secretaría del Patrimonio Nacional, 1965, v. 3, p. 736-738.

${ }^{37}$ Miguel Miramón, carta a Félix Zuloaga, Guanajuato, 13 de agosto de 1858, y Querétaro, 23 de agosto de 1858, AFZ-UIA, caja 1, docs. 363 y 360. 
De conjuras y revueltas. La policía política al acecho

Las detenciones que hemos referido respondieron al temor del gobierno de que ocurriera una asonada general; varios incidentes ocurridos en la ciudad en las semanas previas incrementaron este desasosiego. Así, se había acusado a los liberales de estar detrás del motín que el 9 mayo de 1858 protagonizaron los serenos del alumbrado, y los promotores de las revueltas estudiantiles suscitadas en el mes de julio en los colegios de Minería, Medicina, Agricultura, San Ildefonso y Letrán, hechos por los que se mandó a varios constitucionalistas a la cárcel de Tlatelolco. Es factible que éstos hubiesen provocado los incendios ocurridos en el barrio de Santa Ana y en la plazuela del Jardín en donde "espíritus pusilánimes" hicieron estallar tres bombas. A pesar de que las autoridades afirmaron que la tranquilidad pública estaba asegurada y que los incidentes fueron "travesuras de chiquillos de escuela", al parecer había más de fondo. ${ }^{38}$

El entorno y la desconfianza dieron pie para que el gobierno permitiera el registro de aquellos domicilios en los que según los agentes de la policía se refugiaban enemigos del orden, no quedando exentos los de los funcionarios. Uno de éstos fue el del regidor José María Carballeda, allanado por Juan Lagarde por órdenes de Zuloaga, quien había recibido informes de que ahí se había escondido el jefe liberal Luis G. Picazo, hermanastro del concejal. Días más tarde el presidente mencionó que si bien había permitido la intromisión en la casa de Carballeda, ésta no era la del edil, sino la de uno de sus "varios hermanos", sin especificar cuál de ellos, Pascual, Dolores, Ignacio o Luis, todos ellos relacionados con los emisarios juaristas. ${ }^{39}$

La persecución de los prosélitos constitucionalistas por la policía secreta llevó a ésta a irrumpir los edificios públicos, uno de ellos el de la Diputación, sede del Ayuntamiento. Así ocurrió el sábado 7 de agosto de 1858 cuando Lagarde se presentó en la sala capitular con instrucciones de aprehender al secretario de la corporación, el licenciado Vicente Riva Palacio, a quien trasladó a la prisión de Tlatelolco. Si bien se mencionó que esta detención no había respondido a motivos políticos, hay evidencias de que el munícipe era uno de los empleados del gobierno, imputados por los verdaderos amigos de Zuloaga y por el Diario de Avisos, que trabajaban en la

38 "Incendio", El Siglo Diez y Nueve, 13 de julio de 1858, p. 4, y "Bombas", Diario de Avisos, 3 de agosto de 1858, p. 3.

${ }^{39}$ José María Azcárate, carta a Alejandro Arango y Escandón, México, 26 de julio de 1858, AHDF, Ayuntamiento y Gobierno del Distrito, Serie Ayuntamiento, v. 397, exp. 350, f. 3. 
ciudad de México en favor del partido liberal. ${ }^{40}$ Hechos posteriores confirmarían que Riva Palacio fue uno de los principales agentes que más hicieron por promover revueltas. ${ }^{41}$

Las detenciones que acabamos de referir por parte de la policía secreta nos hacen preguntarnos si el gobierno tenía indicio de que se gestaba un movimiento en la ciudad de México en favor del gobierno de Veracruz y si fue por esta razón que estrechó la vigilancia sobre los familiares y los amigos de los liberales que en aquélla se encontraban, así como la de los presos políticos que estaban en la cárcel de la Acordada, pues a finales del mes de agosto se dispuso que fueran visitados tan sólo un día a la semana. ${ }^{42}$

Considero que las medidas aludidas iban más allá de la sugestión y se sustentaban en los informes que Zuloaga recibió de un posible pronunciamiento. En efecto, el 14 de septiembre Juan Lagarde descubrió una conspiración en la calle de la Pila Seca, cercana al convento de Santo Domingo, que pretendía levantarse durante los festejos por la independencia. En el domicilio encontró una relación con los nombres y direcciones de 211 vecinos "notables" por sus "ideas o riqueza". Con base en las declaraciones de los implicados, se sabe que proyectaban provocar cuatro incendios en distintos puntos de la ciudad a la misma hora en que se encendieran los fuegos artificiales y aprovechar la algarabía popular para ir a las viviendas marcadas en la lista y asesinar a sus moradores. Para realizar lo anterior, repartirían puñales entre los léperos de los barrios "más desmoralizados", a quienes, entre otras cosas, se les permitiría saquear las casas. ${ }^{43}$

De esta confabulación, llamada por las autoridades la "rebelión de la soga y el puñal”, hay varios elementos que debemos considerar. El primero es el número de personas - cuyos nombres no se dieron a conocer-que

40 "Presos", Diario de Avisos, 10 de agosto de 1858, p. 3, y "Prisión”, La Sociedad, 8 de agosto de 1858, p. 4.

${ }^{41}$ AHDF, Ayuntamiento y Gobierno del Distrito, Actas de Cabildo, v. 180A. En la f. 604 de este libro está asentado que el "Srio. Lic. Vicente Riva Palacio estuvo en prisión por causa política del 10 de agosto al 29 de diciembre de 1858”. No sería la última vez, en el transcurso de la guerra de Reforma, que el secretario del Ayuntamiento fuera enviado a prisión acusado de conspirador. Por ese delito se le habría de aprehender en el mes de marzo de 1860 .

42 "Presos", Diario de Avisos, 23 de agosto de 1858, p. 2.

${ }^{43}$ Se hallaron dagas, pistolas, granadas de mano y una bandera roja con un puñal color rojo dibujado en el centro. "Horrible complot descubierto ayer en esta capital", La Sociedad, 15 de septiembre de 1858, p. 3, y Félix Zuloaga, carta a Benito Haro, México, 14 de septiembre de 1858, AFZ-UIA, caja 1, doc. 228; "Caballeros de la soga y el puñal”, Diario de Avisos, 15 de septiembre de 1858 , p. 3. 
debían ser ultimadas, el cual parece elevado. Si bien la prensa apuntó que el plan de la calle de la Pila Seca fue fraguado por los agentes adeptos a la Constitución de 1857, no hay evidencias de que éstos proporcionaran recursos económicos o humanos; además, resulta difícil creer que permitieran el asesinato de vecinos "notables", cuando tenían con ellos vínculos de amistad o parentesco.

Aun cuando algunos miembros del partido conservador opinaron que era necesario "ser estúpido para haber soñado en el triunfo con esos ridículos elementos", otros se mostraron mesurados; uno de ellos fue el presidente Zuloaga, quien consciente del caos que pudo imperar de haberse verificado el motín expresó: "La Providencia nos ha salvado milagrosamente”. Por lo demás, para evitar desórdenes durante las conmemoraciones patrias, el gobierno supremo dispuso que se suspendieron los festejos nocturnos del 15 y 27, días en los que se prohibió a la población disparar armas de fuego y detonar cuetes. ${ }^{44}$

Las detenciones de los liberales que hemos referido y el descubrimiento de la conjura de la calle de la Pila Seca revelan dos cosas: por un lado, que la policía secreta comandada por Juan Lagarde seguía de cerca los movimientos de las personas que, sabía, eran partidarias del gobierno constitucional; y, por el otro, lo eficiente de sus pesquisas. Así tenía que ser, así lo exigía el estado de guerra civil. No menos importante es que estos hechos consolidaron a su jefe como un destacado agente de la administración conservadora, lo que por otra parte le valió su ascenso a coronel de Caballería permanente.

La persecución de los agentes y emisarios constitucionalistas

A pesar de los golpes que la policía secreta había infringido a los satélites liberales, sus esfuerzos parecían estériles debido a que los segundos no se amilanaron y continuaron trabajando desde la clandestinidad. Dos fueron los personajes que asumieron este liderazgo: Francisco Zarco y el ya mencionado Miguel Lerdo de Tejada. El primero relataría años más tarde que una vez que Benito Juárez se instaló en Veracruz lo nombró su agente encubierto en la capital, que en tal carácter se había consagrado a reunir

44 "La solemnidad de anoche", Diario Oficial del Supremo Gobierno, 16 de septiembre de 1858, p. 2. 
fondos para auxiliar a los prisioneros de Estado, socorrer a los jefes militares en sus campañas y pagar informantes. ${ }^{45}$

Una de las tareas más significativas que tuvo fue la de alentar a las guarniciones a sublevarse en contra de la administración de Zuloaga, labor para la cual contó con la ayuda de Lerdo de Tejada, con quien obró siempre de acuerdo. Carmen Blázquez menciona que durante el mes de agosto de 1858, ambos políticos se abastecieron de armas y pólvora y se ocuparon de facilitar las comunicaciones de la ciudad de México con Veracruz, actividades que fueron apoyadas por el ministro estadounidense John Forsyth, quien proporcionó su casa en Tacubaya y aun la legación como centros de operaciones. ${ }^{46}$

Con el éxodo de Lerdo de Tejada en octubre de 1858, después del frustrado ataque del general Miguel Blanco, Zarco quedó como el principal representante liberal, responsabilidad de la que habría de hacerse cargo durante el segundo y tercer año de la guerra. El gobierno, que estaba enterado de esto, le dio instrucciones a Juan Lagarde de buscar al periodista por "todos los rincones de la ciudad"; su captura le interesaba no sólo por el hecho de los informes que comunicaba a Veracruz, sino por sus escritos propagandísticos a través del Boletín Clandestino en el que criticaba y arremetía contra la administración "tacubayista", de la que decía que no era legítima. ${ }^{47}$ La policía secreta siguió la pista del político duranguense por dos años, quien se ocultó en diferentes domicilios de la capital; si bien por momentos estuvo a punto de aprehenderlo, la sagacidad del emisario juarista evitó que esto ocurriera.

La presión de Lagarde no logró quebrantar el brío de Zarco, quien nunca dejó de trabajar para promover un levantamiento en la ciudad de México. Si bien en el primer semestre de 1859, ya durante el gobierno del general Miguel Miramón, su labor y la de los demás agentes liberales disminuyó; ésta habría de intensificarse a finales del propio año de 1859 y principios de 1860; de nueva cuenta casas particulares, plazas y aún las cárceles les

45 “Cuentas", El Siglo Diez y Nueve, 19 de marzo de 1861, p. 3, y Velada pública celebrada por el Liceo Hidalgo, la noche del 13 de abril de 1874, México, "El Porvenir”, 1875, p. 47-48.

${ }^{46}$ Blázquez, Veracruz liberal..., p. 91.

${ }^{47}$ Antonio Albarrán, "Francisco Zarco", en Liberales ilustres mexicanos de la Reforma y la Intervención, México, Comisión Nacional de los Derechos Humanos/Miguel Ángel Porrúa, 2006, p. 245-256. El Boletín Clandestino se distribuía por las noches, y a escondidas, en las calles de la ciudad de México. 
sirvieron de refugio para conspirar. ${ }^{48}$ Lo anterior se dio en gran medida, gracias al contexto nacional en el que el ejército constitucional comenzó a obtener victorias relevantes en el interior del país, lo que los conjurados de la capital trataron de aprovechar, mas, se enfrentaron con la agudeza e intuición de Juan Bautista Lagarde.

En el mes de marzo de 1860, merced a la vigilancia de la policía secreta, se descubrió un depósito de armas que se dijo formaba parte de un movimiento más grande que se preparaba en la ciudad de México. Días más tarde, Lagarde aprehendió a célebres liberales, entre ellos el general Anastasio Parrodi, los coroneles Luis Arrieta y Vicente Sánchez, el capitán Eduardo Fernández, los licenciados Florentino Mercado y Vicente Riva Palacio, así como a Nicanor Carrillo. ${ }^{49}$ En su informe había mencionado que les había recogido correspondencia con personas en el puerto de Veracruz y con agentes de la capital, así como "recibos de cantidades puestas a su disposición y distribuidas por ellos, y otros papeles que los condenan”. Los elementos incautados, al parecer del jefe de la policía, evidenciaban que pretendían sublevarse, por este motivo se les acusó de conspiradores y se pidió que se les castigara conforme a las leyes. ${ }^{50}$

Las capturas del mes de marzo no deben sorprendernos, todo ello por los vínculos que la mayoría de las personas involucradas mantenían con simpatizantes del gobierno constitucional, y porque al menos tres de ellos habían estado en prisión en el transcurso de la guerra por motivos políticos: Arrieta y Sánchez en diciembre de 1858 por promover en la capital el Plan de Navidad, mientras que Riva Palacio, recordemos, por el mismo delito que se le inculpaba en esta ocasión: conspirador. ${ }^{51}$

${ }^{48}$ Felipe Arce y Pesado, carta a Benito Juárez, México, 18 de enero de 1860, en Juárez, Benito Juárez. Documentos..., v. II, p. 574-577.

49 "Depósito de armas", Diario de Avisos, 20 de marzo de 1860, p. 3, y "Prisiones", La Sociedad, 2 de abril y 23 de mayo de 1860, p. 3.

50 "Perturbadores del orden", Diario Oficial del Supremo Gobierno, 2 de abril de 1860, p. 2.

${ }^{51}$ Si bien se envió a Vicente a prisión las relaciones que su padre, Mariano Riva Palacio, mantenía con el entonces presidente Miguel Miramón le permitieron obtener su libertad a los pocos días. Vicente Riva Palacio continuaría trabajando en favor del gobierno constitucional hasta el final de la guerra. Se conoce que dirigió uno de los círculos liberales, de los muchos que existieron, que conspiraron en la ciudad de México, del que formaban parte Manuel Muñiz, Anastasio Zerecero y Joaquín Alcalde, entre otros, sin olvidar que se desempeñaba como segundo en jefe del general Rafael Cuéllar, quien comandaba una guerrilla en el valle de México. 
Los esfuerzos de los liberales fueron estériles. El gobierno intensificó su persecución en el primer semestre de 1860, espacio en el que se envió a prisión a un sinfín de vecinos de la capital; no obstante, las aprehensiones de mayor relevancia, estaban por llegar. Éstas comenzaron el día 21 de abril, al sorprender la policía secreta una casa de la calle de D. Toribio ${ }^{52}$ en la que se encontraban los encargados de imprimir el Boletín de Noticias, uno de los periódicos clandestinos más importantes que distribuían los constitucionalistas; la imprenta fue confiscada mientras que los impresores fueron confinados en la cárcel..$^{53}$ Pero la captura más preciada sobrevino semanas más tarde, cuando Lagarde prendió a Francisco Zarco, considerado por los tacubayistas como "pernicioso a la tranquilidad pública" y el "agente principal", ${ }^{54}$ su captura conmocionó a los diversos grupos de liberales de la ciudad de México y aun al gabinete juarista en Veracruz.

Con ese arresto Juan Lagarde se anotó uno de sus más grandes lauros en su carrera como agente policial, ya que con esa detención no quedaron emisarios liberales en la capital con el peso político y moral del periodista; con ello, la policía secreta que había creado Zuloaga y la que dio continuación Miguel Miramón cumplió el cometido para el que fue erigida: terminar con los grupos y personas que pusieran en peligro la estabilidad de las administraciones que emanaron del Plan de Tacubaya.

La detención del antiguo editor de El Siglo Diez y Nueve, las prisiones y destierros de otros portavoces del gobierno asentado en Veracruz, así como la incautación de las prensas en las que se imprimían los principales órganos de propaganda liberal, El Constitucional y el Boletín de Noticias, hizo creer a Miramón que la sede de su gobierno había quedado libre de peligros y conjuras. No estaba del todo equivocado. La ciudad de México gozaría de algunas semanas de sosiego; sin embargo, éste sería endeble, efímero, todo

${ }^{52}$ En la actualidad corresponde a la avenida José María Izazaga, en el tramo comprendido entre las calles de Simón Bolívar e Isabel la Católica.

53 "Descubrimiento" e "Imprenta clandestina", La Sociedad, 22 y 23 de abril de 1860, p. 3.

54 "D. Francisco Zarco" y “Amaños de los puros”, La Sociedad, 15 y 17 de mayo de 1860, p. 3, y “El Sr. D. Francisco Zarco", Diario de Avisos, 16 de mayo de 1860, p. 3. Es probable que para no ser detenido, Zarco saliera de la ciudad de México en el mes de abril una vez que supo de la aprehensión de Riva Palacio y Parrodi; si bien regresó "de incógnito" fue descubierto por Lagarde el domingo 13 de mayo en casa de Crescencio García. En un primer momento fue recluido en el domicilio de Juan Lagarde, de donde se le envió a la cárcel de la Acordada. Raymond C. Wheat, Francisco Zarco, el portavoz liberal de la Reforma, México, Porrúa, 1957, p. 204, y Albarrán (1957, p. 251). 
ello por el predominio que el ejército constitucional obtuvo en las acciones militares que se desarrollaron en el centro y occidente del país, lo que cambió de manera sustancial el curso de la guerra. La derrota en Calpulalpan de las fuerzas que comandaba Miguel Miramón el 22 de diciembre de 1860 dejó abiertas las puertas de la ciudad de México a Jesús González Ortega, jefe vencedor en aquella acción; con ello, el final de la guerra civil que se había extendido por tres años era un hecho consumado.

El triunfo del gobierno liberal y desarticulación de la policía secreta

Las primeras brigadas liberales hicieron su entrada en la capital la noche del 24 de diciembre. Una de las primeras tareas que emprendió el gobierno constitucional al establecerse en la ciudad de México fue la de aprehender y llevar a juicio a los personajes, ya políticos o militares, que habían colaborado como funcionarios o ministros de Estado, en las administraciones de Félix Zuloaga y Miguel Miramón. Así, se logró la detención de Manuel Piña, José M. Saldívar, Teófilo Marín, Miguel M. Azcárate, Luis G. Cuevas, Manuel Díez de Bonilla, Isidro Díaz, Joaquín y Mariano Miramón y la del general Francisco G. Casanova; a este último se acusó de promover un motín en la capital. ${ }^{55}$

Si bien las aprehensiones referidas fueron importantes, hubo particular interés del gobierno por capturar a los individuos que integraron el cuerpo de policía secreta, sobre quienes pesaban varias y severas acusaciones, la principal: torturar a los presos políticos. La tarea no fue sencilla ya que los antiguos agentes se mantuvieron ocultos en la ciudad de México o en poblaciones cercanas; no obstante, se sabe que algunos de éstos, los más osados, caminaban "públicamente por las calles de la capital, insultando con su presencia a la sociedad civilizada”. Este fue el caso de José María Rubio, segundo de Juan Lagarde, de quien se dijo que se paseaba "descaradamente" por la calzada de la Villa de Guadalupe; si bien en una de sus caminatas el coronel liberal Aureliano Rivera había intentado detenerlo, Rubio se defendió y después de "un combate cuerpo a cuerpo" huyó "gravemente herido" al punto que, se dijo, había perdido una mano. ${ }^{56}$

55 “Aprehensiones" y "Prisiones”, La Reforma, 20 de enero y 6 de febrero de 1861, p. 2 y 3; "Captura importante", El Monitor Republicano, 18 de abril de 1861, p. 3, y "Acusados políticos", El Constitucional, 13 de abril de 1861, p. 3-4.

56 "Bandidos" y "Opinión pública", El Monitor Republicano, 20 y 22 de febrero de 1861, p. 3. En el mismo año de 1861 a Aniceto Mora, agente de la policía secreta, se le siguió un 
De nada sirvieron las prevenciones tomadas por los miembros de la policía secreta del gobierno conservador para no ser capturados; ya fuera por delaciones o bien por la búsqueda exhaustiva de su contraparte liberal, en menos de seis meses se logró prender a los "funestos" y principales colaboradores de Juan Lagarde. En el mes de febrero de 1861 se anunció la detención de Sabás Pérez, considerado "su agente más activo y sanguinario" y "quien le ayudaba a ejercer sus más repugnantes actos de crueldad”; días después se informó públicamente de la captura del "famoso esbirro" José María Perdomo, así como del indulto al que se había acogido su hermano Luis Lagarde. ${ }^{57}$

Si bien los arrestos mencionados fueron importantes, el antiguo jefe de la policía, "el feroz Lagarde", seguía prófugo. Su detención debió apremiar al gobierno debido a las múltiples averiguaciones que había en su contra, tanto por sus atropellos desmedidos como por los tormentos a los que sometió a los reos políticos y a ladrones comunes. ${ }^{58}$ Estas afrentas, insistimos, no eran recientes o se limitaban a la guerra que acababa de concluir, eran el colofón de una larga trayectoria como espía y agente de la policía política, en la que se había distinguido por servir a gobiernos a los que la historia nacional ha denominado dictatoriales y conservadores. Su carrera, como hemos visto, estuvo enmarcada por los abusos y los exacerbados, aunque eficaces, métodos para acabar con los enemigos de las administraciones a las que sirvió.

En este punto debemos preguntarnos ¿qué hizo Juan Lagarde una vez que el ejército liberal entró en la ciudad de México la noche del 24 de diciembre de 1860? Al saberse en la capital la victoria liberal en Calpulalpan los principales funcionarios, ya civiles y militares, así como los allegados del gobierno tacubayista recién exiliado, se apresuraron a abandonarla, siendo uno de ellos el comandante de la policía secreta. Es factible creer

juicio por "proporcionar tormento a los aprehendidos". AGN, Justicia, v. 644, exp. 203, f. 277-279.

57 “Sabás Pérez” y “Aprehensiones”, El Constitucional, 6 y 22 de marzo de 1861, p. 4 y 3, y "Aprehensión importante", El Siglo Diez y Nueve, 5 de marzo de 1861, p. 3. De los hermanos Lagarde, Javier, teniente coronel y comandante militar del Distrito de Tulancingo, también se acogió a la amnistía del gobierno. Por su parte, José Miguel Lagarde, quien se desempeñaba como su segundo en la policía política, había muerto a consecuencia de "un cólico" en el mes de agosto, es decir a escasos meses de concluir la guerra. Tenía 44 años al momento de su deceso. "Defunción”, “Sumisión” y "Acogidos al indulto”, El Siglo Diez y Nueve, 29 de septiembre de 1860, p. 3; 22 y 23 de febrero de 1861, p. 1 y 3. Véase Acta de defunción de José Lagarde. Disponible en: www.familysearch.org/ark:/61903/3:1:S3HT-X3QS-1B3?i=530\&cc $=1615259$

${ }^{58}$ AGN, Justicia, v. 644, exp. 144, f. 189-191. 
que, consciente de que los jefes constitucionalistas no le darían garantías debido a su celebridad como "torturador" de presos políticos, Lagarde, emulando su éxodo del mes de agosto de 1855, se hubiera rasurado su rubia barba para evitar ser reconocido por las partidas federales que proliferaban en la ciudad y sus inmediaciones.

Gracias a la prensa conocemos que entre el 24 y 25 de diciembre Juan Bautista se dirigió a Toluca al frente de una sección de cuerudos, llevando con él varias mulas cargadas con el parque que había logrado sacar de la ciudad de México. Todo indica que su estancia en la capital del Estado de México fue breve y días más tarde se incorporó a las reducidas fuerzas que en el sur reconocieron a Félix Zuloaga como presidente, las que eran comandadas por destacados jefes militares como Leonardo Márquez, Juan Vicario y Marcelino Cobos, que conformaron la "Legión Sagrada", que no era otra cosa que un ejército irregular que sostenía el Plan de Tacubaya de diciembre de 1857. Al lado de éstos, Lagarde habría de permanecer activo, al menos durante los ocho primeros meses de 1861, en poblaciones de la tierra caliente como Cuernavaca, Cuautla, Izúcar e Iguala. ${ }^{59}$

Si bien en más de una ocasión la prensa de la ciudad de México anunció y dio como cierta la noticia de que Juan Bautista había sido aprehendido y pasado por las armas en el sur del país, incluso llegaron a afirmar que el fusilamiento había tenido lugar en el pueblo de Tetecala, esto no pasó de ser un rumor, uno de los incontables que en esa época circulaban en la capital. Ahora bien, el escenario para el antiguo jefe de la policía debió cambiar con el autoexilio que Zuloaga se impuso en La Habana, Cuba, a finales de 1861, esto debido a que su salida ocasionó que los jefes que hasta entonces lo habían acompañado se diseminaran por varios puntos de la república; si bien muchos quedaron en guerra abierta contra la administración de Benito Juárez, Lagarde no siguió a ninguno y todo hace suponer que pasó a la clandestinidad, al menos durante el bienio, 1861-1862, que el gobierno liberal estuvo asentado en la capital del país. ${ }^{60}$

59 "Los prófugos", "Los facciosos” y "Cuernavaca”, La Reforma, 30 de diciembre de 1860, p. 3; 22 y 23 de enero de 1861, p. 3 y 4; “Lagarde”, “D. Félix Zuloaga”, “Trajes”, El Monitor Republicano, 14 de enero de 1861; 4, 5 y 14 de febrero de 1861, p. 3. Las fuerzas de la Legión Sagrada se caracterizaron por vestir una túnica blanca con una cruz roja en el pecho, mientras que sus sombreros llevaban una cinta con la inscripción: "Ni pido ni doy cuartel". "Félix Zuloaga”, El Siglo Diez y Nueve, 4 de febrero de 1860, p. 3.

60 "Lagarde", El Monitor Republicano, 19 de febrero de 1861, p. 2, y "Juan Lagarde” y "D. Juan B. Lagarde”, El Constitucional, 19 y 21 de febrero de 1861, p. 4; y “D. Juan Lagarde”, El Siglo Diez y Nueve, 7 de febrero de 1860, p. 4. 
El final de una trayectoria

A partir de 1862 el originario del puerto de Veracruz desapareció de la escena política, su nombre no volvió a figurar en los cuerpos de policía secreta que se establecieron en la ciudad de México en los años posteriores y se desconoce a qué actividades se dedicó. Resulta interesante y a la vez extraño ver que Lagarde Gassion no colaboró con la Intervención Francesa (1862-1864) ni con el Imperio de Maximiliano de Habsburgo (1864-1867), como sí lo hicieron muchos de sus antiguos correligionarios políticos y militares. No fue sino hasta el año de 1864 que se vuelve a tener noticias de él, esto cuando en el mes de marzo solicitó y obtuvo del Ministerio de Guerra su retiro del ejército para "atender el establecimiento de su salud", la que, había mencionado, se hallaba quebrantada desde años atrás. ${ }^{61}$

El temido, feroz y suspicaz jefe de la policía secreta de la ciudad de México, de la policía "reaccionaria" durante la dictadura santannista y los gobiernos conservadores de Félix Zuloaga y Miguel Miramón habría de permanecer alejado de todo cargo público hasta su deceso ocurrido en su casa de la calle de la Pila Seca, de la capital del país, la noche del 30 de junio de 1869 a consecuencia de un mal cardiaco. ${ }^{62}$ Su muerte apenas fue anunciada en los periódicos de la capital; uno de ellos El Siglo Diez y Nue$v e$, aquel que tanto había sufrido de las vejaciones del "barba rubia" se limitó a mencionar "Séale la tierra leve". Juan Lagarde fue sepultado un día después en el panteón de los Ángeles; su acta de defunción menciona que tenía 44 años. ${ }^{63}$

\section{Consideraciones finales}

En el presente artículo se destacó cómo desde el inicio de la guerra civil en enero de 1858, la ciudad de México, como sede de uno de los gobiernos nacionales que se asumieron como legítimos, experimentó una guerra

${ }^{61}$ AHSDn, Cancelados, exp. III/3-916, t. 1, f. 19, y t. II, f. 181.

${ }^{62}$ Acta de defunción de Juan B. Lagarde. Disponible en: familysearch.org/ark:/61903/3:1:S3HT-X91D-31?i=295\&wc=3PXC-929\%3A122580201\%2C132956101\%3Fcc\%3D1615259\&cc $=1615259$

${ }^{63}$ Ibidem; "Defunción”, El Siglo Diez y Nueve, 6 de julio de 1869, p. 3; "Defunciones”, El Ferrocarril, 3 de julio de 1869, p. 3, y "Defunción”, La Revista Universal, 5 de julio de 1869, p. 3. 
interna, propia, distinta a la que se vivió en el interior del país. Las autoridades ahí establecidas hicieron frente a un enemigo que, aunque sigiloso y prudente, se mantuvo activo, conspirando ya para promover la rebelión de alguna de las guarniciones o bien para facilitar la ocupación de la capital por el ejército constitucional.

Así, los emisarios y agentes liberales representaron un lastre para los gobiernos tacubayistas durante los tres años que duró la contienda civil de Reforma, el que no podía permitir ningún movimiento que pretendiera desestabilizarlo o atentar en su contra. Fue este el motivo por el que el presidente Félix Zuloaga, a la par que se asió de la ciudad de México, estableció un cuerpo de policía secreta, el que a partir de entonces espió, persiguió y envió a la cárcel a un sinfín de enemigos políticos del régimen. Trascendental y atinada fue la designación que como jefe de dicho cuerpo de seguridad hizo en la persona del teniente coronel de caballería Juan B. Lagarde, personaje de vasta experiencia dentro de la policía de la ciudad de México.

Podemos concluir que Juan Lagarde y la policía secreta por él comandada cumplió de manera cabal con el cometido para el que fue creada: diezmar a los emisarios del gobierno antagónico, acabar con las conjuras políticas y militares y evitar insurrecciones, es decir medidas que iban encaminadas a coadyuvar a la consolidación de la administración que emanó del Plan de Tacubaya del 17 de diciembre de 1857. Lo anterior quedó de manifiesto al ver que los principales adeptos del partido liberal, Benito Quijano, Manuel Doblado, Felipe Berriozábal, Juan José Baz, Juan Palacios, Vicente Riva Palacio, entre otros muchos, fueron aprehendidos y enviados a las cárceles, con lo que la policía evitó que sus planes de la ocupación de la capital por el ejército federal fracasaran.

La captura más preciada para la policía política ocurrió en el mes de mayo de 1860 al tomar Lagarde prisionero a su viejo "enemigo" Francisco Zarco. Este suceso, podemos afirmar, marcó el golpe de muerte para los agentes constitucionalistas de la ciudad de México; si bien quedaron muchas personas comprometidas con la administración constitucional, ninguna tuvo el arrastre y peso político y moral del periodista.

Sin duda Juan Lagarde y sus agentes, Rubio, Perdomo, Pérez, así como sus hermanos José y Luis se excedieron y abusaron de la potestad que les fue conferida por el gobierno, mas no debemos olvidar en este punto que la violencia por ellos empleada fue permitida por los presidentes conservadores Zuloaga y Miramón; así lo requería el contexto de guerra civil del 
país y conscientes de que ésta era necesaria para consolidar sus respectivas administraciones. Su labor, a pesar de sus excesos, fue eficiente.

Para finalizar sólo me queda mencionar que Juan Lagarde se convirtió en uno de los personajes más despreciados en la ciudad de México al término de la guerra de Reforma, sobre él recayeron las acusaciones y señalamientos más mordaces, fue él quien cargó con la responsabilidad de las vejaciones que sufrieron los presos políticos al momento de su detención o por las penalidades que padecieron en las cárceles. Lagarde se convirtió en un personaje de no gratos recuerdos a quien acompañó siempre el encono popular "no por su odiosa y odiada misión, sino por el refinamiento de grosería y de crueldad con que siempre procuraba desempeñarla". ${ }^{64}$

\section{FUENTES}

Archivos

Archivo Félix Zuloaga, Universidad Iberoamericana (AFZ-UIA)

Archivo General de la Nación (AGN)

Justicia

Pasaportes y Cartas de Seguridad

Archivo Histórico del Distrito Federal (AHDF)

Actas de Cabildo

Ayuntamiento

Archivo Histórico de la Secretaría de la Defensa Nacional (AHSDN)

Cancelados

Operaciones Militares

Archivo Mariano Riva Palacio, Colección Latinoamericana Nettie Lee Benson, Universidad de Texas, Austin (AMR-CNLB)

Publicaciones periódicas

Boletín de Noticias [Ciudad de México], 1860.

Diario de Avisos [Ciudad de México], 1858-1860.

Diario Oficial del Supremo Gobierno [Ciudad de México], 1858-1860.

64 “Prisión”, El Republicano, 27 de septiembre de 1855, p. 3. 
El Constitucional [Ciudad de México], 1861.

El Monitor Republicano [Ciudad de México], 1851 y 1861.

El Ómnibus [Ciudad de México], 1856.

El Republicano [Ciudad de México], 1856.

El Siglo Diez y Nueve [Ciudad de México], 1856-1858 y 1861.

El Universal [Ciudad de México], 1853.

La Reforma [Ciudad de México], 1860-1861.

La Sociedad [Ciudad de México], 1858-1860.

Bibliografía

Albarrán, Antonio, "Francisco Zarco", en Liberales ilustres mexicanos. De la Reforma y la Intervención, México, Comisión Nacional de los Derechos Humanos/ Miguel Ángel Porrúa, 2006, p. 245-256.

Arellano, Emilio, La nueva república. Ignacio Ramírez, el Nigromante, México, Planeta, 2012.

Ignacio Ramírez, el Nigromante. Memorias prohibidas, México, Planeta, 2009.

Balbontín, Manuel, Memorias del coronel Manuel Balbontín, San Luis Potosí, Tip. de la Escuela I. Militar dirigida por Aurelio B. Cortés, 1896.

Bazant, Jan, Antonio Haro y Tamariz y sus aventuras políticas 1811-1869, México, El Colegio de México, 1985.

Blanco, Miguel, Rectificaciones históricas. Colección de artículos escritos por el C. Miguel Blanco, México, J. S. Ponce de León, impresor, 1871.

BlÁzquez, Carmen, Veracruz liberal, 1858-1860, México, El Colegio de México/ Gobierno del Estado de Veracruz, 1986.

Miguel Lerdo de Tejada: un liberal veracruzano en la política nacional, México, El Colegio de México, 1978.

CAmbre, Manuel, La guerra de Tres Años. Apuntes para la historia de la Reforma, Guadalajara, José Cabrera, 1904.

DíAz, Lilia (introd., selec. y traducción), Versión francesa de México: informes económicos 1851-1867, México, Secretaría de Relaciones Exteriores, 1974.

Echeagaray, Miguel María, Apuntaciones para la defensa del general Echeagaray escritas por el mismo, Guanajuato, Impr. Albino Chagoyán, 1861.

Fowler, Will, Santa Anna, Xalapa, Universidad Veracruzana, 2010.

García Ugarte, Marta Eugenia, Poder político y religioso. México siglo XIX, 2 v., México, H. Cámara de Diputados/Universidad Nacional Autónoma de México/ Miguel Ángel Porrúa, 2010. 
Granados, Luis Fernando, Sueñan las piedras. Alzamiento ocurrido en la ciudad de México, 14, 15 y 16 de septiembre de 1847, México, Era/Consejo Nacional para la Cultura y las Artes/Instituto Nacional de Antropología e Historia, 2003.

Gurza Lavalle, Gerardo, La gestión diplomática de John Forsyth, 1856-1858. Las repercusiones de la crisis regional estadounidense en la política exterior hacia México, México, Secretaría de Relaciones Exteriores, 1997.

Haworth, Daniel S., "Desde los baluartes conservadores: la ciudad de México y la guerra de Reforma (1857-1860)”, Relaciones, v. xxi, n. 84, 2000, p. 95-132.

Hernández López, Conrado, Militares y conservadores en la Reforma y el Segundo Imperio (1857-1867), México, El Colegio de México, 2001.

JuÁrez, Benito, Benito Juárez. Documentos, discursos y correspondencia, 12 v., edición, selección y notas de Jorge L. Tamayo, México, Secretaría del Patrimonio Nacional, 1965, v. III.

Liberales ilustres mexicanos. De la Reforma y la Intervención, México, Comisión Nacional de los Derechos Humanos/Miguel Ángel Porrúa, 2006.

Nacif Mina, Jorge, La policía en la historia de la ciudad de México (1524-1928), México, Departamento del Distrito Federal, Secretaría General de Desarrollo Social, 1986.

Ortiz Monasterio, José, "Patria", tu ronca voz me repetía... Biografía de Vicente Riva Palacio y Guerrero, México, Universidad Nacional Autónoma de México/ Instituto de Investigaciones Dr. José María Luis Mora, 1999.

Portilla, Anselmo de la, Historia de la revolución de México contra la dictadura del general Santa Anna, 1853-1855, México, Imprenta de Vicente García Torres, 1856.

Proceso instruido a los ex-ministros de Estado, señores D. Luis G. Cuevas, D. Manuel Díez de Bonilla, D. Manuel Piña y Cuevas y D. Teófilo Marín, y ex-gobernador del Distrito D. Miguel María Azcárate, acusado de usurpación del poder público por las funciones que desempeñaron en la República entre los años de 1858 y 1860, México, Imprenta de José Mariano Lara, 1861.

Pulido Esteva, Diego, "Policía: del buen gobierno a la seguridad, 1750-1850", Historia Mexicana, n. 239, 2011, p. 1595-1642.

Ross, William John, The Role of Manuel Doblado in the Mexican Reform Movement 1855-1860, Austin, University of Texas, 1967.

TAPIA Chávez, Regina, Las “jornadas” de agosto de 1855 en la ciudad de México. Un estudio de caso de los mecanismos de lo político, y del discurso político de lo social, México, Universidad Nacional Autónoma de México, Facultad de Filosofía y Letras, 2010.

Tella, Torcuato S. di, Política nacional y popular en México, 1820-1847, trad. María Antonia Neira Bigorra, México, Fondo de Cultura Económica, 1994. 
VÁzquez Mantecón, María del Carmen, Santa Anna y la encrucijada del Estado. La dictadura: 1853-1855, México, Fondo de Cultura Económica, 1986.

Velada pública celebrada por el Liceo Hidalgo, la noche del 13 de abril de 1874, México, "El Porvenir", 1875.

Villegas Revueltas, Silvestre, El liberalismo moderado en México, 1852-1864, México, Universidad Nacional Autónoma de México, Instituto de Investigaciones Históricas, 2015.

Wheat, Raymond C., Francisco Zarco, el portavoz liberal de la Reforma, México, Porrúa, 1957. 